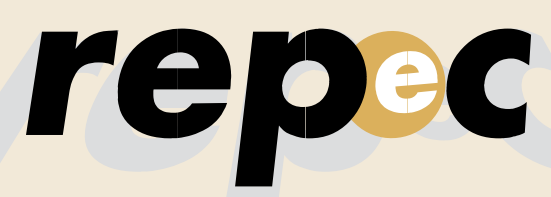

REPeC, Brasília, v. 11, n. 3, art. 6, p. 347-361, jul./set. 2017

Disponivel online em www.repec.org.br

DOl: http://dx.doi.org/10.17524/repec.v11i3.1553
Revista de Educação e Pesquisa em Contabilidade

Journal of Education and Research in Accounting

Periódico Trimestral, digital e gratuito publicado pela Academia Brasileira de Ciências Contábeis

ISSN 1981-8610

\title{
Caso de Ensino: Liquidez ou Solvência, de Quem é a Culpa? A Análise Econômico- Financeira de uma Instituição Financeira
}

\begin{abstract}
Resumo
Objetivo: Este caso de ensino tem como objetivo ilustrar o uso de conceitos associados à liquidez e à solvência para suportar a tomada de decisões estratégicas de longo prazo.
\end{abstract}

Método: Por meio de um caso de ensino, são analisadas questões gerais e específicas para discussão em cursos de graduação e de pós-graduação lato sensu em Ciências Contábeis, Administração e Economia.

Resultados: O Banco Y apresentou rápido crescimento da carteira de crédito, nos últimos anos, apoiado em uma estratégia de alongamento de prazos, que não foi acompanhado na mesma proporção pelo seu patrimônio líquido, levando ao aumento da alavancagem e à compressão do capital regulamentar. Insatisfeitos, os sócios discordavam quanto às causas do insucesso: seria um problema de liquidez, consequência da estratégia de alongamento da carteira de crédito, ou seria um problema de solvência, pois, além de ilíquida, a carteira seria também inadimplente?

Contribuições: A condução dessa análise por meio de um estudo de caso oferece uma perspectiva adicional para a compreensão dos conceitos envolvidos, em especial de liquidez e solvência de instituições financeiras, para além daquela oferecida pela via tradicional da resolução de problemas.

Palavras-chave: Liquidez. Solvência. Risco. Tomada de decisão.
José Américo Pereira Antunes

Doutorando em Ciências Contábeis pela Universidade Federal do Rio de Janeiro (UFRJ). Contato: Av. Presidente Vargas, 730, $15^{\circ}$ Andar, Centro, Rio de Janeiro/RJ, CEP: 20071-900.

E-mail: tesouraria.rj@gmail.com

Renata Sol Leite Ferreira da Costa Doutoranda em Ciências Contábeis pela Universidade Federal do Rio de Janeiro (UFRJ). Contato: Av. República do Chile, $100,2^{\circ}$ Andar, Centro, Rio de Janeiro/RJ, CEP: 20031-917.

E-mail: renatasolcosta@hotmail.com

José Elias Feres de Almeida Doutor em Controladoria e Contabilidade pela Universidade de São Paulo (USP) e Professor na Universidade Federal do Espírito Santos (UFES). Contato: Av. Fernando Ferrari, 514, CCJE, ED-VI, Sala 618, Goiabeiras, Vitório/ES, CEP: 29075-910.

E-mail: joseelias@ccje.ufes.br 


\section{Introdução}

O Banco Y é uma instituição financeira (IF) de médio porte, especializada na concessão de crédito a empresas do segmento de middle market e em operações estruturadas lastreadas em cédulas de crédito bancário (CCB). As CCBs podem ser mantidas em carteira ou cedidas para investidores e fundos de investimento nos quais o Banco Y detém parte das quotas. Suas principais fontes de captação são depósitos a prazo e cessões de crédito para fundos de investimento e fundos de pensão.

$\mathrm{O}$ Banco Y apresentou rápido crescimento da carteira de crédito, nos últimos anos, apoiado em uma estratégia de alongamento de prazos. Esse crescimento não foi acompanhado na mesma proporção pelo seu PL, levando ao aumento de sua alavancagem e à compressão de seu capital regulamentar. Diante do dilema, representado pela capacidade de originar crédito em volume superior ao limite regulamentar para mantê-lo em carteira, o Banco Y adotou como modelo de negócio complementar a distribuição do crédito excedente ao limite regulamentar para investidores qualificados, em especial fundos de pensão (diretamente ou por meio de fundos de investimento). Naturalmente, a alienação desse crédito implicava transferência substancial de riscos e benefícios, de modo a eliminar o impacto no capital regulamentar.

No entanto, a estratégia adotada pelo Banco Y, em conjunto com seu modelo de negócio, mostrou-se insatisfatória. A carteira de crédito revelou-se excessivamente longa e possivelmente inadimplente. As potenciais perdas daí decorrentes poderiam comprometer o capital regulatório do Banco, que emitiria sinais de dificuldade ao mercado. Consequentemente, o risco de uma "corrida" aos depósitos era um dos cenários possíveis e, a depender da intensidade desses resgates, poderia não haveria liquidez disponível para honrar suas obrigações. Nesse caso, a intervenção por parte do regulador não seria mais um risco, mas sim uma certeza.

Cientes da condição do Banco Y, seus sócios discordavam quanto às suas causas: seria um problema apenas de liquidez, consequência da estratégia de alongamento das operações de crédito que permitiu ao banco ampliar rapidamente a carteira, ou seria um problema também de solvência, pois, além de ilíquida, a carteira seria também inadimplente, comprometendo os fundamentos da entidade? Tornava-se fundamental determinar a resposta, pois a solução a ser adotada seria diferente a depender desse diagnóstico.

Dessa forma, os sócios precisavam decidir que rumo tomar. Para auxiliar a tomada de decisão, contrataram uma empresa independente para realizar uma due-dilligence (processo de investigação e auditoria). O trabalho envolvia, além de uma análise dos números de maneira geral, uma análise específica da carteira de crédito, que é o principal negócio da entidade. Como resultado dessa investigação, seria elaborado um parecer sobre a situação do Banco Y, apresentando propostas de solução para os problemas detectados.

A justificativa para o presente estudo baseia-se no fato de que a liquidez e a solvência de empresas são de extrema relevância quando se trata de tomada de decisão na análise da continuidade de entidades, sobretudo de instituições financeiras. Nesse particular, os eventos de crise financeira, são capazes de impactar a vida de milhões de pessoas. A crise subprime em 2008, motivada pela concessão de empréstimos hipotecários de alto risco, culminou na falência do tradicional banco de investimentos Lehman Brothers e na elevada intervenção estatal no sistema financeiro norte-americano. Nesse sentido, a análise dos indicadores de solvência e liquidez assume importância destacada na antecipação de eventos de quebra bancária que possam se desdobrar em crises sistêmicas, afetando o sistema financeiro de maneira ampla. 


\section{Due Dilligence - Visão Geral do Banco Y}

O procedimento de due-dilligence teve início com uma análise fundamentalista dos números do banco. A Tabela 1 apresenta a evolução dos principais saldos contábeis do Banco Y.

Tabela 1

Principais rubricas contábeis, entre dez/2013 e dez/2016 (em milhões de Reais).

\begin{tabular}{llrrrr}
\hline \multicolumn{1}{c}{ Cosif } & \multicolumn{1}{c}{ Rubrica Contábil } & 2013 & 2014 & 2015 & 2016 \\
\hline $1.0 .0 .00 .00-7$ & ATIVOS & 851 & 2.893 & 4.346 & 6.452 \\
\hline $1.1 .0 .00 .00-6$ & Disponibilidades & 6 & 16 & 76 & 54 \\
\hline $1.2 .0 .00 .00-5$ & Aplicações Interfinanceiras de Liquidez & 46 & 125 & 117 & 40 \\
\hline $1.3 .0 .00 .00-4$ & Títulos e Valores Mobiliários (TVM) & 220 & 1.058 & 1.337 & 1.876 \\
\hline $1.3 .100 .00-7$ & TVM - Livres & 126 & 504 & 596 & 941 \\
\hline $1.3 .1 .15 .00-9$ & TVM - Cotas de Fundos de Investimento & 33 & 95 & 270 & 602 \\
\hline $1.3 .2 .00 .00-0$ & TVM - Outros & 61 & 459 & 471 & 333 \\
\hline $1.6 .0 .00 .00-1$ & Operações de Crédito & 462 & 1.592 & 2.729 & 4.410 \\
\hline $1.8 .0 .00 .00-9$ & Outros créditos & 117 & 102 & 87 & 72 \\
\hline $4.0 .0 .00 .00-8$ & PASSIVOS & 789 & 2.740 & 4.029 & 6.012 \\
\hline $4.1 .0 .00 .00-7$ & Depósitos & 509 & 1.996 & 3.002 & 4.479 \\
\hline $4.9 .0 .00 .00-9$ & Outras obrigações & 280 & 624 & 674 & 736 \\
\hline $4.3 .0 .00 .00-5$ & LCA, LCI, Debêntures & - & 120 & 353 & 797 \\
\hline $6.0 .0 .00 .00-2$ & PATRIMÔNIO LíQUIDO & 62 & 153 & 317 & 440 \\
\hline
\end{tabular}

Fonte: elaborado pelos autores.

Pela análise dos dados, verifica-se que o banco Y mantém elevada exposição ao risco de crédito em seu balanço, tanto diretamente, por meio de operações de crédito, quanto indiretamente, por meio de quotas de fundos lastreadas em operações de crédito $^{1}$. Combinados, os dois instrumentos ampliaram a exposição ao risco de crédito em aproximadamente dez vezes em quatro anos ${ }^{2}$. Por outro lado, o Patrimônio Líquido (PL), base do capital regulatório, ampliou-se em apenas sete vezes ${ }^{3}$, revelando um incremento na alavancagem da carteira de crédito em relação ao PL na ordem de $42 \%{ }^{4}$.

Do ponto de vista da liquidez, as informações disponíveis na Tabela 2 são contraditórias. Enquanto os índices baseados nos ativos líquidos (tais como a razão entre os ativos líquidos e o PL e a razão entre os ativos líquidos e os passivos) ficaram relativamente estáveis, comparando-se o ano de 2013 com o de 2016, os índices baseados no caixa livre decresceram significativamente. Esta queda justifica-se pelo critério mais rigoroso utilizado no cálculo destes últimos índices, que não contempla as quotas de fundos de investimento, as quais são consideradas nos índices baseados nos ativos líquidos.

1 Refere-se à Conta Cosif 1.3.1.15.00-9 (TVM - Cotas de Fundos de Investimento).

2 Refere-se à taxa de variação do saldo das rubricas Operações de Crédito e Cotas de Fundos de Investimento de TVM no período: (4.410 + $602) \div(462+33)=10,1$

3 Refere-se à taxa de variação do saldo da rubrica Patrimônio Líquido no período: $440 \div 62=7,1$

4 Alavancagem em 2016: $((4.410+602) \div 440)=11,39$; Alavancagem em 2013: $(462+33) \div 62=7,98$; Alavancagem $2016 \div$ Alavancagem 2013 $=11,39 \div 7,98=1,42$ 
Tabela 2

Indicadores de liquidez, entre dez/2013 e dez/2016.

\begin{tabular}{lrrrr}
\hline \multicolumn{1}{c}{ Rubrica Contábil } & $\mathbf{2 0 1 3}$ & $\mathbf{2 0 1 4}$ & $\mathbf{2 0 1 5}$ & $\mathbf{2 0 1 6}$ \\
\hline Ativos Líquidos $^{\psi} / \mathrm{PL}$ & $438,7 \%$ & $783,6 \%$ & $482,6 \%$ & $447,7 \%$ \\
\hline Caixa Livre $^{\omega} / \mathrm{PL}$ & $287,1 \%$ & $421,5 \%$ & $248,9 \%$ & $235,2 \%$ \\
\hline Índice de Liquidez(1): Ativos Líquidos / Passivos & $34,4 \%$ & $43,7 \%$ & $37,9 \%$ & $32,7 \%$ \\
\hline Índice de Liquidez(2): Caixa Livre / Passivos & $22,6 \%$ & $23,5 \%$ & $19,6 \%$ & $17,2 \%$ \\
\hline
\end{tabular}

${ }^{\psi}$ Ativos líquidos são o somatório de disponibilidades, aplicações interfinanceiras de liquidez e títulos e valores mobiliários (TVM). ${ }^{\omega}$ Caixa Livre é o somatório de disponibilidades, aplicações interfinanceiras de liquidez e TVM - Livres. Exclui, portanto, as cotas de fundos, as quais não são ativos líquidos.

Fonte: elaborado pelos autores.

O índice de liquidez calculado a partir dos ativos líquidos foi reduzido de $34,4 \%$ para $32,7 \%$. Como a participação das quotas de fundos de investimento no total de Títulos e Valores Mobiliários (TVMs) passou de 15,0\% em 2013 para 32,1\% em 2016, o índice de liquidez (2) calculado a partir do caixa livre (que exclui as quotas de fundos) foi reduzido de $22,6 \%$ para 17,2\%, representando uma severa queda da liquidez do Banco Y. Dessa forma, o risco do Banco Y não satisfazer o eventual resgate de suas captações deixava-o na iminência de uma crise de liquidez.

A Tabela 3 abaixo apresenta o comportamento do Índice de Basiléia (IB) e do Patrimônio de Referência $(\mathrm{PR})^{5}$ do Banco $\mathrm{Y}$, assim como de seus principais componentes. Os valores observados em relação a esses indicadores são bem menos preocupantes que os de liquidez observados na Tabela 2. A redução do IB de 17,6\% em 2013 para 14,5\% em 2016 é compreensível e revela uma preocupação com a rentabilidade do capital, e não indica ser um problema de solvência, uma vez que o valor do IB para 2016 (14,5\%) encontrava-se bem acima do piso regulamentar de $11 \%$.

Tabela 3

Comportamento do capital regulatório e índices de solvência, entre dez/2013 e dez/2016 (em milhões de Reais)

\begin{tabular}{lrrrr}
\hline \multicolumn{1}{c}{ Rubrica Contábil } & $\mathbf{2 0 1 3}$ & $\mathbf{2 0 1 4}$ & $\mathbf{2 0 1 5}$ & $\mathbf{2 0 1 6}$ \\
\hline Patrimônio de Referência (PR) $^{\psi}$ & 124 & 289 & 587 & 869 \\
\hline PR Nível I & 83 & 227 & 499 & 747 \\
\hline PR Nível II & 41 & 62 & 88 & 122 \\
\hline Índice de Basiléia $^{\infty}$ & $17,6 \%$ & $11,7 \%$ & $13,8 \%$ & $14,5 \%$ \\
\hline
\end{tabular}

\% o patrimônio de referência é a soma do PR Nível I e do PR Nível II.

$\Omega$ o PR Nível I é formado pelo somatório do Capital Principal e do Capital Complementar, e corresponde à parcela menos volátil do PL, como o capital social e as reservas de lucros.

w o PR Nível II é composto da Dívida Subordinada da IF, e corresponde à parcela mais volátil do PL, como as reservas de capital e os ajustes de avaliação patrimonial.

Fonte: elaborado pelos autores.

A composição do resultado contábil, nos últimos quatro anos reflete a transformação que a estrutura patrimonial do Banco Y sofreu no mesmo período. O crescimento acelerado das atividades do Banco, em especial da carteira de crédito, levou o lucro líquido de $\mathrm{R} \$ 8,6$ milhões, em 2013, para $\mathrm{R} \$ 89,4$ milhões, em 2015. Como um reflexo do rendimento da carteira de crédito, da aplicação em TVMs e da prestação de serviços de estruturação de operações de crédito (venda de operações de crédito para fundos de investimento), a rentabilidade atingiu 19,7\% do PL no exercício de 2015.

5 O Patrimônio de Referência não corresponde ao PL contábil. É o patrimônio para fins regulatórios e admite a inclusão de determinados passivos (captações), apresentando, em geral, saldo superior ao do PL contábil. 
Em 2016, não obstante o incremento significativo de suas receitas de intermediação financeira, o Banco Y registrou um lucro líquido $29 \%$ inferior ao ano anterior, em função do incremento nas perdas estimadas com créditos de liquidação incerta, nas despesas de captação e nas despesas administrativas. De fato, as despesas administrativas corresponderam a mais de duas vezes o resultado de intermediação financeira do Banco. Além disso, o lucro antes do imposto de renda foi $85 \%$ inferior ao do ano anterior, conforme demonstrado na Tabela 4.

Tabela 4

\section{Demonstração de resultados, entre dez/2013 e dez/2016 (em milhares de Reais)}

\begin{tabular}{|c|c|c|c|c|}
\hline & 2013 & 2014 & 2015 & 2016 \\
\hline Rendas de Operações de Crédito & 207.446 & 161.354 & 466.906 & 722.036 \\
\hline $\begin{array}{l}\text { Resultado de Despesas e Reversões de Provisão para } \\
\text { Créditos de Difícil Liquidação }\end{array}$ & $(12.043)$ & $(75.381)$ & $(92.867)$ & $(172.633)$ \\
\hline Rendas de Títulos e Valores Mobiliários & 42.609 & 66.976 & 121.715 & 191.178 \\
\hline Rendas de Câmbio e Aplicações em Moedas Estrangeiras & 39.629 & 24.043 & 30.831 & 36.388 \\
\hline Receitas da Intermediação Financeira & 277.641 & 176.992 & 526.585 & 776.969 \\
\hline Despesas de Captação & $(124.366)$ & $(136.977)$ & $(342.917)$ & $(556.865)$ \\
\hline Despesas de Câmbio & (3.075) & $(16.083)$ & $(15.502)$ & $(25.334)$ \\
\hline Despesas da Intermediação Financeira & $(127.441)$ & $(153.060)$ & $(358.419)$ & (582.199) \\
\hline RESULTADO DE INTERMEDIAÇÃO FINANCEIRA & 150.200 & 23.932 & 168.166 & 194.770 \\
\hline Receitas de Serviços & 66.164 & 142.605 & 141.872 & 195.046 \\
\hline Resultado de Participações Societárias & $(72)$ & 51.688 & 135.366 & 145.985 \\
\hline Outras Receitas Operacionais & 591 & 1.075 & 2.651 & 8.429 \\
\hline Despesas Administrativas & $(189.820)$ & $(135.262)$ & $(320.838)$ & $(470.473)$ \\
\hline Outras Despesas Operacionais & $(17.535)$ & $(23.774)$ & $(46.830)$ & $(60.494)$ \\
\hline Outras Receitas / Despesas Operacionais & $(140.672)$ & 36.332 & (87.779) & $(181.507)$ \\
\hline RESULTADO OPERACIONAL & 9.528 & 60.264 & 80.387 & 13.263 \\
\hline Receitas Não Operacionais & 1.476 & 531 & 3.920 & 10.164 \\
\hline Despesas Não Operacionais & (38) & (340) & $(821)$ & $(11.303)$ \\
\hline Resultado Não Operacional & 1.438 & 191 & 3.099 & (1.139) \\
\hline LUCRO ANTES DO IMPOSTO DE RENDA & 10.966 & 60.455 & 83.486 & 12.124 \\
\hline Imposto de Renda e Contribuição Social & $(2.381)$ & $(12.028)$ & 5.962 & 51.105 \\
\hline LUCRO LÍQUIDO & 8.585 & 48.427 & 89.448 & 63.229 \\
\hline
\end{tabular}

Fonte: elaborado pelos autores.

Os sócios, após o encerramento do exercício findo em 31 de dezembro de 2016, convocaram uma Assembleia Geral Extraordinária (AGE) a fim de debater a situação do Banco Y. Eles perceberam a necessidade de rever sua estratégia e, consequentemente, seu modelo de negócios e, para isso, deliberaram e aprovaram, na AGE, a contratação de uma empresa especializada em análise financeira e em auditoria. Esta empresa deveria emitir uma opinião isenta, em especial sobre a sua carteira de crédito, visto que não havia consenso entre os sócios sobre os motivos que levaram o Banco Y à situação atual. 


\section{Due Dilligence - Visão Específica do Banco Y: a Carteira de Crédito}

O expressivo aumento da carteira de crédito do Banco Y ocorreu como uma consequência da concessão de operações excessivamente longas e com fluxos financeiros deslocados para o final dos contratos. Tal configuração de carteira impôs à entidade uma condição de baixa geração de caixa nos ativos de crédito, exigindo sucessivas rolagens dos passivos até sua maturação. Do ponto de vista regulatório, a estratégia do Banco era lucrativa, pois operações longas e ilíquidas são bem remuneradas e o reflexo no resultado e no capital regulamentar mostrava-se positivo. Contudo, do ponto de vista de liquidez, representava elevada exposição a uma eventual crise de confiança que lhe drenasse os depósitos, além do risco de inadimplência.

Considerando o exposto, o caso do Banco Y é emblemático. O crescimento expressivo de sua carteira de crédito concentrou-se em operações longas, sobretudo associadas ao desenvolvimento de projetos imobiliários. Tais operações caracterizam-se pelo deslocamento dos fluxos de recebimento para o final dos contratos, em média de três a cinco anos, quando os projetos maturam, bem como pela baixa participação de outros bancos no financiamento da operação. A conjugação dessas características criou dois problemas para o Banco Y: (i) o descasamento dos vencimentos entre ativos e passivos, o qual impõe rolagens sucessivas dos passivos até a maturação dos ativos, o que é considerado crítico para bancos que não dispõem de rede de agências e que, por consequência, não possuem acesso facilitado a passivos estáveis; e (ii) a baixa visibilidade do risco de crédito do cliente, uma vez que a baixa frequência e a pouca representatividade dos fluxos de pagamentos impedem o acompanhamento mais próximo e retardam ações visando a mitigação do risco e/ou a recuperação do crédito.

A Tabela 5 apresenta a evolução da participação de clientes exclusivos (devedores apenas do Banco Y), concentrados (mais de $90 \%$ da exposição no sistema financeiro nacional desses clientes é devida ao Banco Y) e comuns (a exposição é compartilhada com outras IFs). A participação de clientes comuns na carteira do banco Y refluiu de 70,4\% em dez/2013 para 45,5\% em dez/2016, tendo essa redução sido absorvida por clientes exclusivos e concentrados, que evoluíram de $29,2 \%$ para $54,4 \%$ no mesmo período.

Tabela 5

Distribuição da carteira de crédito (CA) por situação de clientes, entre dez/2013 e dez/2016 (em milhares de Reais)

\begin{tabular}{lcccccccc} 
& \multicolumn{2}{c}{ dez/2013 } & \multicolumn{2}{c}{ dez/2014 } & \multicolumn{2}{c}{ dez/2015 } & \multicolumn{2}{c}{ dez/2016 } \\
\hline Situação de Clientes & CA & $\%$ & CA & $\%$ & CA & \multicolumn{1}{c}{$\%$} & \multicolumn{1}{c}{ CA } & $\%$ \\
\hline Clientes Exclusivos & 54.072 & 11,7 & 210.183 & 13,2 & 439.421 & 16,1 & 1.076 .071 & 24,4 \\
\hline Clientes Concentrados & 80.877 & 17,5 & 374.190 & 23,5 & 679.602 & 24,9 & 1.323 .038 & 30,0 \\
\hline Clientes Comuns & 325.358 & 70,4 & 1.004 .739 & 63,1 & 1.607 .572 & 58,9 & 2.006 .608 & 45,5 \\
\hline Outros & 1.849 & 0,4 & 3.184 & 0,2 & 2.729 & 0,1 & 4.411 & 0,1 \\
\hline Total & \multicolumn{2}{c}{462.156} & \multicolumn{1}{c}{1.592 .296} & 2.729 .324 & & 4.410 .128 \\
\hline
\end{tabular}

Fonte: Elaborado pelos autores.

O Banco Central do Brasil exige que as IFs classifiquem seus créditos em nove níveis, em ordem decrescente de risco, incluindo-se, créditos que não estão em atraso (AA e A) atrasos de até 60 dias (B e C), atrasos entre 61 e 120 dias (D e E) e atrasos acima de 121 dias (E em diante). A Tabela 6 apresenta o comportamento da distribuição da carteira de crédito do Banco Y em níveis de risco no período entre dezembro de 2013 e dezembro de 2016. Observa-se um aumento da parcela da carteira classificada nos piores níveis de risco ( $\mathrm{D}$ em diante), que passou de 3,9\% para 59,7\% do total no período. Além de vencimentos longos e todas as consequências de liquidez daí decorrentes, a carteira do banco também apresentou problemas de inadimplência, o que a tornou duplamente problemática. 
Tabela 6

Distribuição da carteira ativa por níveis de risco, entre dez/2013 e dez/2016 (em milhares de Reais)

\begin{tabular}{crrrrrrrr}
\hline \multirow{2}{*}{ Nível de Risco } & \multicolumn{2}{c}{ dez/13 } & \multicolumn{2}{c}{ dez/14 } & \multicolumn{2}{c}{ dez/15 } & \multicolumn{2}{c}{ dez/16 } \\
\cline { 2 - 11 } & \multicolumn{1}{c}{ CA } & \% & CA & \% & CA & \% & CA & $\%$ \\
\hline AA & 81.339 & 17,6 & 584.373 & 36,7 & 1.154 .504 & 42,3 & 136.714 & 3,1 \\
\hline A & 176.544 & 38,2 & 487.243 & 30,6 & 892.489 & 32,7 & 687.979 & 15,6 \\
\hline B & 160.830 & 34,8 & 328.013 & 20,6 & 251.098 & 9,2 & 471.884 & 10,7 \\
\hline C & 25.419 & 5,5 & 108.276 & 6,8 & 207.429 & 7,6 & 480.704 & 10,9 \\
\hline D & 5.546 & 1,2 & 30.254 & 1,9 & 51.857 & 1,9 & 851.155 & 19,3 \\
\hline E & 1.849 & 0,4 & 41.400 & 2,6 & 40.940 & 1,5 & 723.261 & 16,4 \\
\hline F & 462 & 0,1 & 1.592 & 0,1 & 68.233 & 2,5 & 335.170 & 7,6 \\
\hline G & 4.159 & 0,9 & 158 & 0,0 & 27.293 & 1,0 & 401.322 & 9,1 \\
\hline H & 6.008 & 1,3 & 10.987 & 0,7 & 35.481 & 1,3 & 321.939 & 7,3 \\
\hline Total & 462.156 & & 1.592 .296 & & 2.729 .324 & & 4.410 .128 & \\
\hline
\end{tabular}

Notas: i) CA, carteira de crédito ativa; ii) os níveis de risco AA, A, B, C, D E, F, G e H exigem provisões mínimas sobre o saldo devedor da operação de, respectivamente, $0 \%, 0,5 \%, 1 \%, 3 \%, 10 \%, 30 \%, 50 \%, 70 \%$ e $100 \%$.

Fonte: elaborado pelos autores.

A Tabela 7 apresenta o Índice de Realização de Crédito (IRC) de sete IFs ao longo do segundo semestre de 2016. O IRC é a razão entre o fluxo recebido na carteira de crédito, ou seja, o total de reembolsos, e o fluxo esperado. Representa, portanto, o percentual de realização financeira associada à carteira de crédito no mês. O Banco Y apresenta IRC bastante inferior ao dos demais bancos, todos atuantes no mesmo segmento de mercado. Esse indicador é de interpretação bastante imediata e denota uma frustração nas expectativas de recebimento do Banco $\mathrm{Y}$, as quais se mostram bem abaixo dos seus principais concorrentes. No segundo semestre de 2016, o indicador não superou 60\% em nenhum mês, enquanto seu pior concorrente neste quesito, o Banco 5, não teve IRC inferior a 70\%.

Tabela 7

Comportamento do IRC entre Pares, entre julho de 2016 e dezembro de 2016 (em \%).

\begin{tabular}{lcccccc}
\hline \multicolumn{1}{c}{ Banco } & Mês 1 & Mês 2 & Mês 3 & Mês 4 & Mês 5 & Mês 6 \\
\hline Banco 1 & 92,0 & 93,5 & 86,8 & 93,5 & 93,6 & 94,9 \\
\hline Banco 2 & 89,7 & 90,0 & 84,9 & 102,2 & 92,5 & 90,1 \\
\hline Banco 3 & 89,4 & 93,4 & 86,2 & 93,4 & 90,0 & 87,8 \\
\hline Banco 4 & 72,7 & 79,0 & 83,6 & 83,0 & 84,1 & 83,9 \\
\hline Banco 5 & 71,1 & 79,6 & 71,8 & 70,5 & 79,8 & 73,8 \\
\hline Banco 6 & 83,6 & 78,2 & 75,6 & 76,9 & 76,3 & 79,1 \\
\hline Banco Y & 58,4 & 46,8 & 47,4 & 51,5 & 53,1 & 59,0 \\
\hline
\end{tabular}

Fonte: elaborado pelos autores. 
A Tabela 8 complementa a análise estritamente financeira iniciada na Tabela 7. Conquanto a primeira confronte recebimentos efetivos com expectativas de recebimentos, ela nada diz quanto à relevância desses recebimentos em relação ao total da carteira. É possível que um elevado IRC, denotando efetivo cumprimento de expectativas de recebimento, represente um percentual insignificante da carteira, e por fim, seja menos representativo em termos financeiros que um IRC menor, mas substancial frente ao estoque de crédito que o originou. Dessa forma, para uma visão financeira completa da carteira de crédito, é necessário considerar o Índice de Liquidez de Crédito (ILC), que relaciona os fluxos recebidos ao estoque de crédito, refletindo o quanto da carteira foi monetizado no mês. O Banco Y apresenta um ILC desprezível comparado aos seus concorrentes, não tendo alcançado no último semestre de 2016 um ILC acima de $1 \%$, enquanto seu concorrente de pior desempenho (Banco 5) não teve ILC abaixo de 3,3\%. Assumindo esse comportamento como padrão, a maturidade efetiva da carteira seria infinita, o que significa que seu saldo cresceria indefinidamente, uma vez que os valores recebidos não correspondem, nem mesmo, aos juros apropriados nas operações.

Tabela 8

Comportamento do ILC entre Pares, entre julho de 2016 e dezembro de 2016 (em \%).

\begin{tabular}{lcccccc}
\hline Banco & Mês 1 & Mês 2 & Mês 3 & Mês 4 & Mês 5 & Mês 6 \\
\hline Banco 1 & 7,7 & 6, & 8,4 & 11,4 & 7,0 & 9,2 \\
\hline Banco 2 & 6,7 & 7,2 & 4,8 & 8,8 & 8,1 & 8,7 \\
\hline Banco 3 & 6,8 & 6,6 & 5,2 & 5,7 & 5,9 & 7,6 \\
\hline Banco 4 & 5,6 & 5,7 & 4,6 & 6,3 & 4,2 & 8,7 \\
\hline Banco 5 & 5,4 & 6,4 & 5,8 & 6,4 & 3,3 & 4,2 \\
\hline Banco 6 & 7,2 & 6,0 & 5,8 & 6,1 & 5,5 & 6,2 \\
\hline Banco Y & 0,2 & 0,2 & 0,2 & 0,3 & 0,6 & 0,9 \\
\hline
\end{tabular}

Fonte: elaborado pelos autores.

A geração de caixa do Banco Y certamente não é suficiente para a manutenção dos negócios do banco, que necessitava recorrer a outros meios para honrar suas necessidades de caixa.

A due-dilligence ainda não havia sido concluída quando os sócios, preocupados com os crescentes problemas e a tensão envolvendo os negócios do banco, solicitaram o material que havia sido produzido até aquele momento para que eles próprios formassem um juízo de valor sobre a situação da entidade.

\section{Questões para discussão}

Para o desenvolvimento do caso, são propostas a seguir questões gerais e específicas para a resolução, a fim de atingir o objetivo do exercício.

\subsection{Questões gerais}

1. Qual o papel da regulação bancária baseada em solvência e de que maneira ela se propõe a minimizar o risco de uma quebra bancária?

2. Considerando que a "matéria-prima" da indústria bancária é a liquidez, qual a sua contribuição à análise econômico-financeira de uma IF?

3. Afinal, o problema do Banco Y era de solvência, de liquidez ou ambos? 


\subsection{Questões específicas}

1. O texto descreve em detalhes o descasamento entre o crescimento do PL e o dos ativos operacionais (operações de crédito e cotas de fundo de investimento). Que medidas poderiam ter sido consideradas pelo Banco Y para reduzir essa assimetria?

2. Considerando a estratégia adotada pelo Banco $Y$ e assumindo ausência de restrições para a ação do regulador bancário, qual medida poderia ter sido imposta por este último e o que poderia ter evitado o excessivo descasamento de maturidades assumido pelo Banco Y?

3. Considerando que a baixa liquidez da carteira de crédito do Banco Y decorria não apenas da estratégia de alongamento das operações em busca de maiores retornos, mas também da inadimplência, que medida o Banco poderia ter tomado para reconhecer suas perdas sem que isso denotasse problemas financeiros?

\section{Notas de ensino}

Neste tópico estão expostas as características e ações que permeiam o caso de ensino aqui proposto. Inicialmente são apresentados os objetivos educacionais, a seguir o referencial teórico, uma sugestão para um plano de ensino e, por fim, a análise das questões gerais e específicas para o caso.

\subsection{Objetivos educacionais}

Trata-se de um caso instrumental, centrado na análise das implicações de variáveis associadas aos conceitos de liquidez e solvência, envolvendo uma firma bancária. O caso apresenta a evolução do comportamento operacional da entidade, com destaque para a carteira de crédito. $\mathrm{O}$ caso foi concebido para discussão em cursos de graduação e de pós-graduação lato sensu em Ciências Contábeis, Administração e Economia.

Como requisito à discussão do caso de ensino em sala de aula, é necessário revisitar os conceitos de liquidez e solvência, além de outros específicos à indústria bancária. Desta forma, deve ser feita uma revisão sob uma perspectiva generalista, nos moldes da análise econômico-financeira tradicional, assim como sob uma perspectiva específica, considerando-se as particularidades do segmento bancário. Cabe ainda uma breve discussão em torno das justificativas conceituais para regular um mercado e dos instrumentos adotados na regulação bancária, podendo ser abordados aspectos como as crises que acometeram as instituições financeiras, em especial as mais recentes, que culminaram em uma regulação muito maior neste mercado, demonstrando a sensibilidade deste segmento.

De posse desses elementos, os alunos terão condições de avançar com desenvoltura pelo caso e, ao final deste, terão condições de compreender: (i) as implicações da solvência e da liquidez no equilíbrio financeiro de uma IF; (ii) as implicações do descasamento de liquidez em uma IF; (iii) as consequências do alongamento excessivo e da baixa geração de caixa de uma carteira de crédito para o risco de liquidez de uma IF; e (iv) a impossibilidade da regulação bancária baseada em solvência capturar o risco de liquidez incorrido por uma IF. 


\subsection{Referencial teórico}

\subsubsection{Causas da falência bancária: o dilema entre solvência e liquidez}

Os bancos são transformadores de maturidades: converter passivos líquidos em ativos ilíquidos é a razão da existência de um banco e é também a característica que viabiliza a intermediação financeira (Diamond \& Dybvig, 1983). Contudo, o papel de provedor de liquidez assumido pelos bancos implica a internalização da transformação de maturidades na figura do descasamento de liquidez e, consequentemente, tornam-se vulneráveis às corridas bancárias. Minsky (1986) endereçou esse descasamento estrutural em sua "Hipótese de Fragilidade Financeira", na qual os bancos são considerados intrinsecamente frágeis, uma vez que o horizonte de maturação dos ativos é, necessariamente, mais longo que o dos passivos, exigindo, em alguma medida, a rolagem desses últimos. Quanto maior esse descasamento, maior a fragilidade financeira da entidade.

As instituições financeiras prometem a seus clientes de conta corrente acesso instantâneo ao seu dinheiro e, ao mesmo tempo, fazem empréstimos de longo prazo a empresas e indivíduos. Essa incompatibilidade entre a liquidez dos passivos do banco (depósitos) e a maior parte de seus ativos (empréstimos) só é possível, pois o número de depositantes é suficientemente grande para que o banco possa ter certeza que todos não irão retirar o seu dinheiro ao mesmo tempo (Brealey, Myers \& Allen, 2011).

Um sistema financeiro operacional e saudável é essencial ao desenvolvimento econômico. As sucessivas falências bancárias ao longo da história motivaram a constituição de salvaguardas que minimizassem o efeito desses eventos na economia. A primeira dessas contramedidas foi o auxílio de liquidez, mais tarde denominado "Empréstimo de Última Instância", e a criação de bancos centrais como órgãos responsáveis pela coordenação dessas intervenções. Na sequência, foi estabelecida a proteção ao depositante, um seguro de valor limitado destinado a ressarcir os depositantes de bancos insolventes. Por fim, e de maneira mais ampla, constituiu-se a regulação bancária, um conjunto de dispositivos normativos e de supervisão com o propósito de agir prudencialmente e evitar a falência bancária. Apesar disso, temos diversos casos de IFs que, mesmo após a regulação mais severa, foram à falência.

Todavia, não existe consenso acerca dos eventos que disparam a falência bancária e, em consequência, a regulação deste setor oscila entre abordagens distintas com efeito prático discutível.: ora o foco está na transformação de maturidades, e a regulação volta-se para a liquidez, ora o foco está na proteção ao depositante e a regulação volta-se para a solvência.

No passado, com o propósito de minimizar o descasamento de liquidez entre ativos e passivos, o sistema financeiro foi fatiado em nichos específicos de mercado, os quais poderiam ser explorados por tipos definidos de instituições financeiras. Esse modelo de "arquitetura financeira" foi adotado em uma versão branda nos Estados Unidos (Lei Glass-Steagal/1933) e em uma versão mais severa no Brasil, conforme Lei no ${ }^{\circ}$.595/1964. Na versão brasileira, os passivos eram também predefinidos, limitando o descasamento de liquidez à força em vários nichos de mercado.

Mais recentemente, a proteção ao depositante, como estratégia para minimizar o risco de uma corrida de saques, passou a dominar o cenário regulatório, consolidando uma visão de solvência. $\mathrm{O}$ requerimento mínimo de capital baseado em risco, nos moldes definidos pelos Acordos de Capital da Basileia, tornou-se o eixo regulatório central. A crise financeira internacional desencadeada em 2008 e o fracasso da regulação em antecipá-la, ou mesmo em minimizar seus efeitos, impôs uma revisão da abordagem então vigente. Embora a regulação baseada em risco/solvência tenha sofrido diversos reparos, ela não foi abandonada. Todavia, o pêndulo oscilou novamente para a liquidez e a perspectiva é por uma abordagem conjunta solvência/liquidez a ser implantada nos próximos anos. 
Outro aspecto importante no confronto entre solvência e liquidez remete à natureza das informações que compõem esses indicadores. O Índice de Basileia (IB), tido como indicador de solvência por excelência, é de natureza econômica e apresenta forte viés contábil. Sua dinâmica de formação privilegia saldos e resultados contábeis, deixando em segundo plano os aspectos financeiros intrínsecos à atividade bancária. É, portanto, passível de manipulação, na medida em que há larga discricionariedade na apuração do resultado contábil na atividade bancária, seja no ajuste a mercado de ativos e passivos financeiros (em especial os de nível 3 na hierarquia de valor justo, que são mensurados com a utilização de premissas internas e não de dados observáveis em mercado, havendo um elevado grau de subjetividade), seja na constituição de provisões para perdas estimadas com créditos de liquidação incerta. E essa possibilidade ganha contornos de certeza na medida em que o IB é o sinalizador de saúde bancária internacionalmente aceito. Assim, a manutenção do IB em patamares satisfatórios, ou pelo menos acima do piso regulamentar, é uma estratégia de sobrevivência adotada pelas IFs (Francis \& Osborne, 2012).

Por outro lado, índices de liquidez podem ser elaborados a partir de informações menos sujeitas à manipulação e, por conseguinte, mais confiáveis, principalmente no segmento bancário, onde as reservas de liquidez são usualmente constituídas de ativos financeiros facilmente verificáveis. É de se supor, portanto, que índices de liquidez apresentem potencial explicativo superior ao IB, no caso de avaliação da situação econômico-financeira de IFs.

Além disso, conforme destacam Brealey et al. (2011), devemos ter em conta quando avaliamos a liquidez de uma empresa que ativos que, aparentemente, são líquidos, por vezes, têm o mau hábito de se tornarem ilíquidos, como ocorreu durante a crise subprime das hipotecas em 2008, em que algumas instituições financeiras criaram fundos conhecidos como veículos de investimento estruturado (structured investment vehicles - SIVs), emitindo dívidas de curto prazo apoiadas em hipotecas residenciais. Como as taxas de inadimplência de hipotecas começaram a subir, o mercado destes títulos de dívida deixou de ser atrativo e os investidores, obrigados a vender seus papéis, constataram que tais títulos valiam menos da metade do valor nominal.

\subsubsection{O crédito e suas implicações na solvência e na liquidez}

A análise vencimento médio de uma carteira de crédito é bastante ilustrativa em relação às implicações da solvência e da liquidez para a estabilidade ou fragilidade de uma instituição financeira.

Desconsiderando o risco de crédito e, por extensão, o efeito das perdas estimadas com créditos de liquidação incerta, o alongamento do prazo da carteira de crédito não compromete em qualquer medida a apropriação de renda. Ao contrário, como a apropriação de renda se dá por competência e independe da efetiva geração de caixa, o resultado contábil produzido pela carteira de crédito será melhor quanto maior for o prazo médio dessa carteira, uma vez que ficará mais tempo exposta ao efeito dos juros. O mesmo raciocínio é aplicável para o reflexo no capital regulamentar, cujo elemento central é o PL, e o insumo mais relevante é o resultado contábil. O alongamento da carteira de crédito, portanto, gera efeitos positivos tanto no resultado quanto no capital regulamentar, que dele deriva.

Contudo, o mesmo não pode ser dito acerca da liquidez dessa carteira, aqui considerada sob o prisma da geração de caixa. Minsky (1986), em sua "Hipótese de Fragilidade Financeira", propõe a existência de três tipos de estruturas de financiamento de posições ativas no mercado: hedge, especulativa e ponzi. Tais estruturas caracterizam-se por diferentes relações entre os fluxos de caixa esperados decorrentes da atividade operacional da empresa ou de ativos financeiros por ela detidos, e os fluxos de caixa a serem desembolsados para honrar obrigações contratadas para financiá-los. 
A estrutura hedge apresenta compatibilidade temporal entre os fluxos de caixa dos ativos e dos passivos que os financiam, sendo insensível a choques externos de liquidez, ou seja, ela é estável financeiramente. A estrutura especulativa, por sua vez, apresenta descasamento desfavorável entre os fluxos de caixa ativos e passivos e necessita que os passivos sejam refinanciados até que os ativos maturem e gerem caixa suficiente para honrá-los. Essa estrutura é vulnerável a choques externos de liquidez, uma vez que a recusa dos credores em rolar suas posições levaria à inadimplência da firma. Por fim, a estrutura ponzi é o extremo de iliquidez do espectro, não havendo qualquer geração de caixa nos ativos até sua maturação. Nesse período, os passivos terão que ser refinanciados por um número indefinido de vezes, até que ocorra a geração de caixa ativa suficiente para honrá-los.

Delimitando a generalização de Minsky (1986) para a indústria bancária e limitando os ativos geradores de caixa às carteiras de crédito, observamos a coexistência dos três regimes de financiamento com predominância do regime especulativo. Nesse sentido, é razoável supor que a composição das carteiras de crédito segundo os regimes de financiamento é condição fundamental para determinar o grau de estabilidade financeira da IF e do sistema financeiro como um todo. Nesse sentido, quanto maior a participação de regimes especulativos e ponzi na carteira de crédito de uma IF, maior sua vulnerabilidade a choques externos e menor sua estabilidade financeira.

A análise das estruturas financeiras propostas por Minsky (1986) como ativos de crédito permitiria reescrevê-las como segue: (i) operações de crédito que financiam atividades que geram caixa suficiente para cumprir os compromissos contratuais configuram uma estrutura hedge; (ii) operações de crédito que financiam atividades que geram caixa no longo prazo e demandam constantes refinanciamentos de curto ou médio prazos correspondem à estrutura especulativa (a viabilidade dessa estrutura depende de uma geração de caixa capaz de honrar os juros da dívida e de um funcionamento normal dos mercados que permita que o principal da dívida seja renegociado); e (iii) operações de crédito que financiam atividades tomando por base o valor das garantias constituídas ao invés da antecipação dos fluxos de caixa esperados, configuram uma estrutura ponzi. A viabilidade desta estrutura de financiamento, que pode surgir a partir de uma renegociação de uma unidade especulativa que tenha sofrido deterioração, depende do valor esperado do ativo dado em garantia (Minsky, 1986).

Para ilustrar o argumento, simulamos o comportamento, do ponto de vista do resultado e da liquidez (geração de caixa), de um banco cujo único ativo é uma carteira de crédito e o exibimos na Figura 1. A carteira de crédito em questão obedece a uma estrutura de financiamento ponzi, não havendo pagamentos, nem de juros nem de principal, na janela de análise.

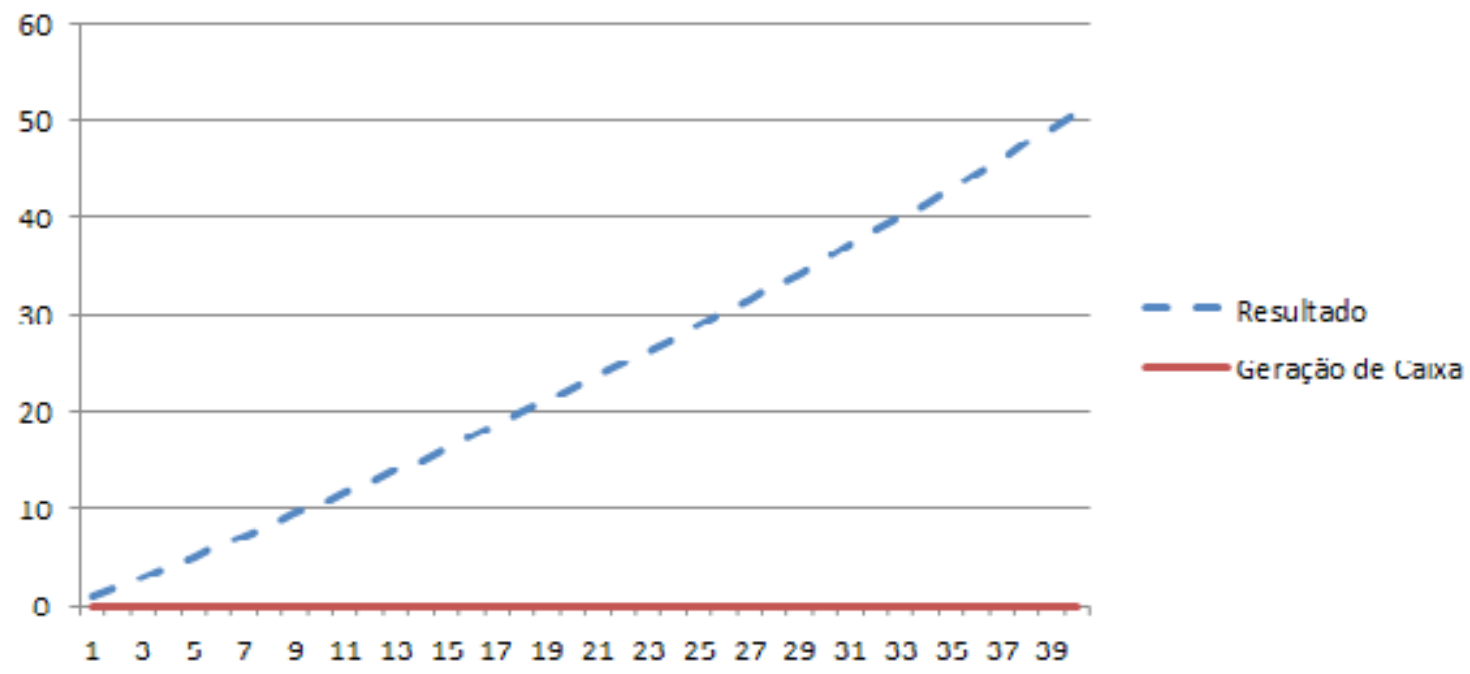

Figura 1. Resultado contábil e geração de caixa de um ativo com vencimento infinito Fonte: elaborado pelos autores. 
Os comportamentos do resultado e da geração de caixa são radicalmente opostos: enquanto o resultado apropriado na carteira de crédito amplia-se significativamente, a geração de caixa é nula. Em consequência, o capital da entidade e, consequentemente, sua solvência é inflado, ao passo que não há liquidez, uma vez que o ativo em questão é ilíquido. Dessa forma, a manutenção de ativos ilíquidos concorre para tornar a entidade mais solvente, embora ilíquida, o contrário do que se deveria esperar para uma IF.

Fica evidente que, à medida que a carteira de crédito torna-se mais ilíquida, maior é a dependência da IF em relação à disposição de seus credores em financiá-la. Dito de outra forma, quanto mais ilíquida, maior a fragilidade financeira da IF frente a choques externos.

\subsection{Sugestão para um plano de ensino}

Este caso foi projetado para ser utilizado em uma sessão de cento e vinte minutos, envolvendo a discussão de conceitos de liquidez e solvência e sua implicação na viabilidade de uma firma bancária. $\mathrm{O}$ estudo do caso deve ser realizado com alunos familiarizados com conceitos de análise econômico-financeira, uma vez que a discussão extrapola os conceitos gerais de liquidez e solvência para as peculiaridades de uma instituição financeira.

As informações apresentadas no caso, sobretudo quanto à carteira de crédito, não pertencem ao cotidiano dos alunos. Portanto, o caso deve ser entregue com antecedência para que seja estudado e a bibliografia envolvida seja consultada previamente. A discussão de eventos conhecidos de falência ou "quebra" de instituições financeiras, além das graves crises financeiras por trás delas, também é interessante e motivará maior envolvimento dos alunos com o caso.

A sessão pode ser iniciada com a discussão do caso em pequenos grupos durante cerca de $30 \mathrm{mi}$ nutos. O objetivo dessa fase inicial é solicitar aos alunos que se posicionem quanto à situação de liquidez e de solvência do Banco Y e as razões que fundamentam essa posição. Concluída essa fase, o professor pode fazer uma pergunta genérica à turma, do tipo: "Afinal, o problema do Banco Y é de solvência ou de liquidez?", apresentando as razões que sustentam uma e outra opção.

É bastante razoável que haja uma polarização entre as alternativas e o papel do professor será mediar essa discussão oferecendo elementos que corroborem ou refutem as assertivas formuladas. O professor poderá exemplificar os argumentos dos alunos com casos conhecidos de falências de instituições financeiras, relacionando-os com liquidez ou solvência, conforme o caso.

O desfecho do caso não deverá centrar-se na opção por uma das alternativas. Como visto no item 4.2.1 do referencial teórico, liquidez e solvência são conceitos relacionados e não antagônicos. $\mathrm{O}$ argumento decisivo está na maior eficiência da avaliação da situação econômico-financeira de uma entidade do ponto de vista da liquidez do que do ponto de vista da solvência, em especial tratando-se de uma instituição financeira, visto que a liquidez envolve menos julgamentos, menos discricionariedade, pois está apoiada em elementos, em geral, mais facilmente observáveis, mais próximos da realidade de mercado. Por outro lado, a solvência é consequência de julgamentos não necessariamente observáveis. O componente de resultado que contribui significativamente para a formação da solvência é derivado do regime de competência, o qual, como observado no item 4.2.2 do referencial teórico, pode levar a conclusões equivocadas quanto ao equilíbrio financeiro de uma entidade, tanto mais se o objeto de análise for uma instituição financeira. 


\subsection{Propostas de encaminhamento para as questões}

\subsubsection{Questões gerais}

1. A regulação baseada em solvência apoia-se na premissa de que haveria um capital ótimo, o qual seria suficiente para suportar os riscos incorridos por uma instituição financeira. Esse capital deve corresponder a 11\%, no mínimo, dos ativos ponderados pelo risco, nos moldes do Acordo de Capital da Basileia II. A aplicação desse percentual mínimo garante uma alavancagem máxima de 9,09 vezes entre os ativos ponderados pelo risco e o capital regulatório.

Ao limitar a exposição a risco ao nível de cada firma bancária, pretende-se minimizar seu risco de quebra e, por extensão, o risco de contágio dessa quebra às demais firmas bancárias, o denominado risco sistêmico.

2. A liquidez oferece uma mensuração mais precisa da situação econômico-financeira de um banco e poderia atuar de maneira complementar a solvência. Bancos são intermediários financeiros e, como tais, dispensam, teoricamente, a necessidade de capital, uma vez que apenas transferem liquidez entre os agentes superavitários e deficitários da economia. Contudo, ao acessarem recursos da sociedade, expõem os depositantes a um risco de perda que deve ser minimizado. Daí as diversas salvaguardas adotadas, sendo o capital mínimo, ou o capital regulatório, uma delas. Contudo, a solvência é um indicador estático, que não reflete com eficiência a dinâmica da intermediação financeira. Indicadores como a geração de caixa da carteira de crédito, que é um indicador de liquidez dinâmico, são mais apropriados para informar quanto ao risco de crédito do banco, assim como sua expectativa em relação ao comportamento da economia como um todo. Como foi visto no caso do Banco Y, o fato de uma IF ser líquida de acordo com o índice previsto no Acordo de Basileia, não necessariamente implica que ela possua geração de caixa suficiente para a manutenção de suas operações.

3. A diferença entre liquidez e solvência está mais na dimensão temporal que na conceitual. É como se a liquidez se comportasse como uma solvência de curto prazo. Além disso, o tempo se encarrega de converter uma na outra. Segundo Goodhart (2008), liquidez e solvência são gêmeas e frequentemente indistinguíveis. Um banco ilíquido pode rapidamente tornar-se insolvente e um banco insolvente, ilíquido. O que importa destacar é que o encaminhamento do problema é diferente. Se o diagnóstico fosse de um problema de liquidez, o banco poderia alongar também seus passivos e limitar a constituição de novas operações de crédito longas. Progressivamente, o descasamento de prazos e o risco de liquidez decorrente seriam minimizados. No caso de um problema de solvência, a solução envolveria medidas mais drásticas, como um aporte de capital dos sócios e o reconhecimento imediato das perdas em operações de crédito. Esses argumentos serão explorados nas questões específicas.

\subsubsection{Questões específicas}

1. A originação de crédito do Banco $\mathrm{Y}$, a uma taxa maior que o aumento de seu capital, foi acentuada pela estratégia de alongamento de carteira de crédito. Quanto mais longo um crédito, mais tempo é necessário para sua realização financeira. A manutenção do crédito por mais tempo no Balanço Patrimonial gera mais rendas de crédito, porém onera o capital regulatório, pois o crédito é um ativo de risco com ponderação significativa. Dessa forma, uma maneira de minimizar o descasamento entre ativos de risco (crédito) e o capital regulatório seria reduzir a maturidade média da carteira de crédito, compensando o apetite do Banco Y por novas originações. Sua estratégia de investimento em fundos de pensão também deve ser criticada, visto que tais investimentos são menos capazes de compensarem riscos de crédito, visto que seu funding é de longo prazo, havendo um risco maior de inadimplência (default). 
2. O descasamento de maturidades é um problema de liquidez por excelência. Dessa forma, o regulador poderia ter imposto limites objetivos ao alongamento da carteira de crédito, minimizando o risco de liquidez.

3. A inadimplência da carteira de crédito é um problema de solvência. Dessa forma, a medida saneadora envolve necessariamente o reconhecimento dessas perdas, o qual deve ser feito concomitantemente com um aporte de capital compatível com essas perdas. Essa medida seria bastante interessante, uma vez que endereçaria também a questão da liquidez, pois aportes de capital em instituições financeiras são feitos necessariamente em dinheiro.

\section{Referências}

Brealey, R. A.; Myers, S. C.; Allen, F. (2011). Principles of Corporate Finance (10ª ed.). Nova Iorque: McGraw-Hill Irwin.

Diamond, D.; Dybvig, P. (1983). Bank runs, deposit insurance, and liquidity. Journal of Political Economy, 91(3), p. 401-419. DOI: https://doi.org/10.1086/261155.

Francis, W. B.; Osborne, M. (2012). Capital requirements and bank behavior in the UK: Are there lessons for international capital standards? Journal of Banking \& Finance, 36(3), p. 803-816. DOI: https:// doi.org/10.1016/j.jbankfin.2011.09.011.

Goodhart, C. (2008). Liquidity risk management. Financial Stability Review, 11, Banque de France, fev.

Minsky, H. (1986). Stabilizing an unstable economy. New Haven: Yale University Press. 